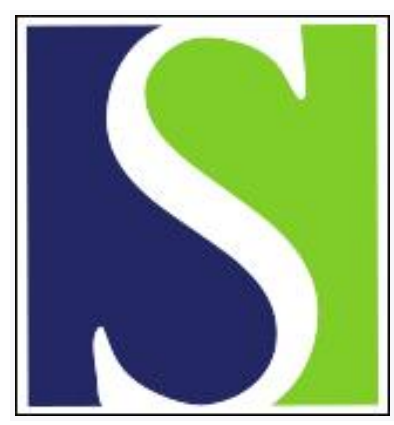

Scand J Work Environ Health 2000;26(3):257-262

https://doi.org/10.5271/sjweh.540

Issue date: Jun 2000

Radiographic knee osteoarthritis in floorlayers and carpenters

by Kirkeskov Jensen L, Mikkelsen S, Loft IP, Eenberg W, Bergmann I, Løgager V

Key terms: clinical examination; compositor; knee osteoarthrosis; knee-straining work; questionnaire; radiological investigation; self-assessment; self-report; self-reported knee complaint

This article in PubMed: www.ncbi.nlm.nih.gov/pubmed/10901119

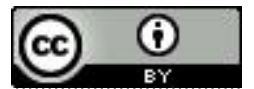




\title{
Radiographic knee osteoarthritis in floorlayers and carpenters
}

\author{
by Lilli Kirkeskov Jensen, MD, ${ }^{1,2}$ Sigurd Mikkelsen, DM, ${ }^{1}$ Inger P Loft, MSc, ${ }^{1}$ Winnie Eenberg, BSc, ${ }^{1}$ Inge \\ Bergmann, MD, ${ }^{3}$ Vibeke Løgager, $M D^{3}$
}

\begin{abstract}
Kirkeskov Jensen L, Mikkelsen S, Loft IP, Eenberg W, Bergmann I, Løgager V. Radiographic knee osteoarthritis in floorlayers and carpenters. Scand J Work Environ Health 2000:26(3):257-262.

Objectives The aim of the present study was to examine the relationship between knee-straining work and radiological findings of knee osteoarthritis and to study the relation between radiological findings and self-reported knee complaints and clinical signs of knee osteoarthritis.

Methods The material consisted of 133 floorlayers, 506 carpenters, and 327 compositors, 26-72 years of age, who had completed a questionnaire and reported no previous knee trauma. A stratified sample of these questionnaire respondents, 50 floorlayers, 51 carpenters, and 49 compositors, were radiologically examined for knee osteoarthritis by 2 radiologists. The X-ray films were independently assessed by 2 radiologists and blinded with respect to knee complaints, trade, and age.

Results The radiological investigation showed estimated prevalences of knee-osteoarthritis (grades $2-4$ ) for $14 \%$ of the floorlayers, $8 \%$ of the carpenters, and $6 \%$ of the compositors (not significantly different). For the subjects $\geq 50$ years of age the estimated prevalences of the combination of radiological grades $2-4$ for knee osteoarthritis and knee complaints during the last 12 months were $29 \%$ [95\% confidence interval (95\% CI) 17 $44 \%$ ], $9 \%(95 \% \mathrm{CI} 1-26 \%)$, and $1 \%(95 \% \mathrm{CI} 1-10 \%)$ for the floorlayers, carpenters, and compositors, respectively. Radiological grades $2-4$ were mainly found for subjects above the age of 50 years, subjects with knee complaints, and floorlayers. Radiological knee osteoarthritis was positively associated with self-reported knee complaints and with clinical signs of intraarticular and retropatellar crepitation.

Conclusions The data suggest that work in which a considerable amount of time is spent in knee-straining positions may be a risk factor for the development of knee osteoarthritis above the age of 50 years.
\end{abstract}

Key terms clinical examination, compositors, knee osteoarthrosis, knee-straining work, questionnaire, radiological investigation, self-reported knee complaints.

Previous studies have shown an increased frequency of radiological knee osteoarthritis among miners $(1,2)$, pipefitters, and welders (3), possibly related to kneeling or squatting. However, the amount of knee-straining work in these trades was poorly described. A study of floorlayers, including a quantitative description of kneestraining work, was negative, but this study included only subjects below 50 years of age (4).

The purpose of the present study was to examine the relation between knee-straining work and knee complaints, physical findings indicating knee disorders, and radiological knee osteoarthritis. Knee-straining work was defined as work in kneeling, knee-supporting (weightbearing on the knees), or squatting work positions. The study was a cross-sectional study of male floorlayers, carpenters, and compositors between 26 and 72 years of age. The results concerning the amount of knee-straining work in the 3 trades, knee complaints, and physical findings have been published separately (5). Video recordings of representative work tasks showed that the floorlayers had knee-straining work in 56\% of their workhours, and the corresponding figure for carpenters was approximately $25 \%$. Compositors had no knee-straining work (5).

\section{Subjects and methods}

The study material consisted of 133 floorlayers, 506 carpenters, and 327 compositors who had completed a questionnaire on aspects of their work, knee complaints,

1 Clinic of Occupational Medicine, Glostrup Hospital, Glostrup, Denmark.

2 Department of Occupational and Environmental Medicine, Skive Hospital, Skive, Denmark.

3 Department of Radiology, Glostrup Hospital, Glostrup, Denmark.

Reprint requests to: Dr Lilli Kirkeskov Jensen, Department of Occupational and Environmental Medicine, Skive Sygehus, Resenvej 25, DK-7800 Skive, Denmark. [E-mail: SSAMALKJ@vibamt.dk] 
previous knee trauma, medical conditions, height, weight, smoking, and participation in sports. The subjects with a previous knee trauma (eg, meniscal lesions and ligamental ruptures) and those with diseases such as rheumatoid arthritis and gout were excluded. The clinical study included 295 subjects, selected at random with variable sample fractions from 9 strata defined by the 3 trades and the following 3 categories of knee complaints: never, previously but not within the last 12 months, within the last 12 months. A sample of subjects participating in the clinical study was further invited to participate in the radiological examination. These subjects were invited at random from the 9 strata, aiming at a total of 50 subjects for each trade and in such a way that approximately $2 / 3$ within each trade were selected from subjects who had had knee complaints within the last 12 months. Clinical findings were not considered in the selection of the subjects. The study material is presented in table 1 .

Table 1. Results of the radiological examinations by sampled strata (trade and knee complaints during the last 12 months), age, and selected combined strata. $(95 \% \mathrm{Cl}=95 \%$ confidence interval)

\begin{tabular}{|c|c|c|c|c|c|}
\hline \multirow{2}{*}{$\begin{array}{l}\text { Complaints } \\
\text { during the last } \\
12 \text { months }\end{array}$} & \multirow{2}{*}{$\begin{array}{c}\text { Questionnaire } \\
\text { respondents } \\
\text { total }(\mathrm{N})\end{array}$} & \multirow{2}{*}{$\begin{array}{c}\text { Sample } \\
\text { for X-ray } \\
\text { (N) }\end{array}$} & \multicolumn{3}{|c|}{$\begin{array}{l}\text { Knee osteoarthritis } \\
\text { grades } 2-4\end{array}$} \\
\hline & & & $N$ & $\%$ & $95 \% \mathrm{Cl}$ \\
\hline \multicolumn{6}{|l|}{ No } \\
\hline \multicolumn{6}{|l|}{ Floorlayers } \\
\hline $\begin{array}{l}<50 \text { years } \\
\geq 50 \text { years } \\
\text { All }\end{array}$ & $\begin{array}{l}33 \\
29 \\
62\end{array}$ & $\begin{array}{r}5 \\
13 \\
18\end{array}$ & $\begin{array}{l}- \\
1 \\
1\end{array}$ & $\begin{array}{r}0 \\
8 \\
4^{\mathrm{a}}\end{array}$ & $\begin{array}{l}0-48 \\
3-28 \\
2-23\end{array}$ \\
\hline \multicolumn{6}{|l|}{ Carpenters } \\
\hline $\begin{array}{l}<50 \text { years } \\
\geq 50 \text { years } \\
\text { All }\end{array}$ & $\begin{array}{r}196 \\
95 \\
291\end{array}$ & $\begin{array}{r}10 \\
5 \\
15\end{array}$ & $\begin{array}{l}1 \\
- \\
1\end{array}$ & $\begin{array}{r}10 \\
0 \\
7^{a}\end{array}$ & $\begin{array}{l}1-43 \\
0-51 \\
0-31\end{array}$ \\
\hline \multicolumn{6}{|l|}{ Compositors } \\
\hline $\begin{array}{l}<50 \text { years } \\
\geq 50 \text { years } \\
\text { All }\end{array}$ & $\begin{array}{l}120 \\
158 \\
278\end{array}$ & $\begin{array}{r}9 \\
10 \\
19\end{array}$ & $\begin{array}{l}- \\
1 \\
1\end{array}$ & $\begin{array}{r}0 \\
10 \\
6^{\mathrm{a}}\end{array}$ & $\begin{array}{l}0-32 \\
1-43 \\
0-25\end{array}$ \\
\hline \multicolumn{6}{|l|}{ Yes } \\
\hline \multicolumn{6}{|l|}{ Floorlayers } \\
\hline $\begin{array}{l}<50 \text { years } \\
\geq 50 \text { years } \\
\text { All }\end{array}$ & $\begin{array}{l}46 \\
25 \\
71\end{array}$ & $\begin{array}{l}21 \\
11 \\
32\end{array}$ & $\begin{array}{l}- \\
7 \\
7\end{array}$ & $\begin{array}{r}0 \\
64 \\
22^{\mathrm{a}}\end{array}$ & $\begin{array}{c}0-11 \\
40-84 \\
13-35\end{array}$ \\
\hline \multicolumn{6}{|l|}{ Carpenters } \\
\hline $\begin{array}{l}<50 \text { years } \\
\geq 50 \text { years } \\
\text { All }\end{array}$ & $\begin{array}{r}154 \\
61 \\
215\end{array}$ & $\begin{array}{l}18 \\
18 \\
36\end{array}$ & $\begin{array}{l}1 \\
4 \\
5\end{array}$ & $\begin{array}{r}6 \\
22 \\
10^{a}\end{array}$ & $\begin{array}{c}1-26 \\
10-43 \\
4-25\end{array}$ \\
\hline \multicolumn{6}{|l|}{ Compositors } \\
\hline $\begin{array}{l}<50 \text { years } \\
\geq 50 \text { years } \\
\text { All }\end{array}$ & $\begin{array}{l}18 \\
30 \\
48\end{array}$ & $\begin{array}{l}13 \\
17 \\
30\end{array}$ & $\begin{array}{l}1 \\
1 \\
2\end{array}$ & $\begin{array}{c}8 \\
6 \\
7^{a}\end{array}$ & $\begin{array}{l}6-22 \\
3-20 \\
4-15\end{array}$ \\
\hline \multicolumn{6}{|l|}{ Total } \\
\hline Floorlayers & 133 & 50 & 8 & $14^{b}$ & $8-24$ \\
\hline Carpenters & 506 & 51 & 6 & $8^{b}$ & $3-18$ \\
\hline Compositors & 326 & 49 & 3 & $6^{\mathrm{b}}$ & $2-16$ \\
\hline
\end{tabular}

$\mathrm{X}$-rays of the anteroposterior and lateral positions of the knees were taken while the subject was lying down. The X-rays were assessed independently by 2 medical specialists in radiology (IB, VL) and were made without knowledge of the subject's trade, age, or reported knee complaints. In case of disagreement on the grade, a final joint assessment was made. The assessments were carried out according to the criteria defined by Kellgren \& Lawrence (6), which categorize knee osteoarthritis by severity as follows: grade $0=$ no changes, grade $1=$ doubtful narrowing of joint space and possible osteophytic lipping, grade $2=$ definite osteophytes and possible narrowing of joint space, grade $3=$ moderate multiple osteophytes, definite narrowing of joint space and some sclerosis and possible deformity of bone ends, grade 4 = large osteophytes, marked narrowing of joint space, severe sclerosis, and definite deformity of bone ends.

\section{Reproducibility of the radiological assessment}

The agreement between the assessments of knee osteoarthritis by the 2 radiologists is shown in table 2 . The kappa-coefficient was 0.52 [95\% condifence interval $(95 \%$ CI) $0.43-0.61]$ if all grades were considered and 0.61 ( $95 \%$ CI $0.44-0.78$ ) if the grades were dichotomized as grades $0-1$ and $2-4$.

\section{Analysis}

The grades of knee osteoarthritis were dichotomized by merging grades 0 and 1 and grades 2 through 4 . There were only 3 subjects with knee osteoarthritis of grades $2-4$ among the subjects who never had knee complaints or not within the last 12 months, and these 2 complaint groups were also merged. Each of the resulting 6 strata (3 trades combined with 2 self-reported complaint categories) were further subdivided into 2 age groups, $<50$ years and $\geq 50$ years.

The population prevalence of knee osteoarthritis in a specific stratum was estimated by the proportion of subjects with knee osteoarthritis in the sample. When strata were combined, the estimation of the population

Table 2. Agreement between the radiologists' assessment (grades $0-4$ ) of knee osteoarthritis ( $\mathrm{N}=300$ knees). ${ }^{\mathrm{a}}$

\begin{tabular}{lrrrrr}
\hline Radiologist 2 & \multicolumn{5}{c}{ Radiologist 1 } \\
\cline { 2 - 6 } & 0 & 1 & 2 & 3 & 4 \\
\cline { 2 - 6 } 0 & 178 & 37 & 2 & - & - \\
1 & 11 & 42 & 5 & - & - \\
2 & 1 & 8 & 7 & 1 & - \\
3 & - & 1 & 2 & 2 & - \\
4 & - & - & - & 2 & 1 \\
\hline agreement 230/300=77\%; kappa=0.52 (95\% confidence interval \\
0.43-0.61).
\end{tabular}


prevalence in the combined group (eg, trade) must consider the various sampling fractions of the specific strata. The following notation is used: $N_{i}$ is the number of subjects in the $i$ 'th stratum in population $N, n_{i}$ is the number of subjects in the sample in the $i$ 'th stratum, and $x_{i}$ is the number of subjects with knee osteoarthritis of grades 2-4 in the $i$ 'th stratum. For combined strata, the estimated prevalence $[\mathrm{E}(\mathrm{p})]$ in the population is as follows:

$$
E(p)=\Sigma v_{i} E\left(p_{i}\right),
$$

where $v_{i}=N_{i} / N$ and $E\left(p_{i}\right)=x / n_{i}$

The $95 \%$ confidence intervals for the estimated prevalences were calculated using the hypergeometric distribution. For combined strata, we can only be certain of a significant difference for 2 prevalence estimates if the 95\% confidence intervals do not overlap. The significance of differences between prevalences in 2 specific strata was assessed by Fisher's exact test.

\section{Results}

The prevalences of knee osteoarthritis of grades $2-4$ for all the specific strata and certain combined strata are shown in table 1.

Altogether 17 subjects ( 8 floorlayers, 6 carpenters, and 3 compositors) were ranked as radiological grades $2-4$. Four of the 8 floorlayers but no carpenters or compositors were grades $3-4$. Among the subjects below the age of 50 years, 3 subjects ( 2 carpenters, 1 compositor) were ranked grade 2 , and none were grade 3 or 4 . Among the subjects without knee complaints within the last 12 months, 3 were ranked grade 2 , and none were grade 3 or 4 . Thus grades $2-4$ of knee osteoarthritis were mainly found among symptomatic subjects above the age of 50 years.

\section{Knee osteoarthritis and trade}

The prevalence estimates of radiological knee osteoarthritis of grades $2-4$ for the 3 trades are shown in table 1. The prevalence estimates were $14 \%, 8 \%$, and $6 \%$ for the floorlayers, carpenters, and compositors, respectively, but with considerable overlap of the confidence intervals. For the subjects $\geq 50$ years of age the estimated prevalences ( 2 complaint strata combined) were $34 \%$ (95\% CI $20-50 \%), 9 \%(95 \%$ CI $2-26 \%)$, and $9 \%(95 \%$ CI $3-28 \%$ ) for the respective trades. These results were derived by merging the strata specified in table 1 .

For subjects $\geq 50$ years of age, the estimated prevalences of the combination of radiological knee osteoarthritis grades 2-4 and knee complaints during the last 12 months were $29 \%$ (95\% CI $17-44 \%$ ), $9 \%$ (95\% CI
$1-26 \%)$, and $1 \%(95 \% \mathrm{CI} 1-10 \%)$ for the floorlayers, carpenters, and compositors, respectively. The figures can be derived by combining strata for subjects $\geq 50$ years of age in table 1. [For example, for floorlayers $7 \mathrm{sub}$ jects out of the 11 in the X-rayed sample of 25 symptomatic subjects $\geq 50$ years of age had knee osteoarthritis, grades $2-4$; thus the estimated frequency was (7/11) $\mathrm{x}$ 25 among a total of 54 subjects $\geq 50$ years of age (29\%)].

\section{Knee osteoarthritis and age}

Among the subjects $<50$ years of age there were only 3 cases with radiological knee osteoarthritis among 76 subjects examined (3.9\%), as compared with 14 cases among 74 subjects $\geq 50$ years of age $(19 \%)$. The prevalence of knee osteoarthritis for floorlayers $\geq 50$ years of age $(34 \%$, $95 \%$ CI $20-50 \%$ ) was significantly different from that of floorlayers $<50$ years of age $(0 \%, 95 \% \mathrm{CI} 0-10 \%)$. For carpenters and compositors, the differences between the prevalences of the 2 age groups were not significantly different, but the numbers were small. These results are based on 2 complaint strata and can be derived from table 1 .

\section{Knee osteoarthritis and complaints}

The relation between knee complaints during the last 12 months and radiological knee osteoarthritis is shown in table 1 . For symptomatic subjects $\geq 50$ years of age, the prevalence of knee osteoarthritis was $64 \%, 22 \%$, and $6 \%$ for the floorlayers, carpenters, and compositors, respectively. The difference in the prevalence between the floorlayers and compositors was significant $(\mathrm{P}=0.002$, Fisher's exact test). The difference between the floorlayers and carpenters was "borderline" significant $(\mathrm{P}=0.05)$. The difference between the carpenters and compositors was not significant $(\mathrm{P}=0.34)$. For subjects $<50$ years of age the numbers were small, and there were no significant differences in the prevalence of knee osteoarthritis among the subjects with and subjects without knee complaints for any of the 3 trades.

\section{Knee osteoarthritis and clinical findings}

Table 3 shows the frequencies of knee osteoarthritis among the subjects with and without clinical signs of intraarticular crepitation, retropatellar crepitation, and pain by knee bending. For both of the 2 clinical investigators a significant positive association was found between radiological knee osteoarthritis grades $2-4$ and intraarticular crepitation in the physical examination (prevalence rate ratios 4.3 and 5.1). A similar association was found for retropatellar crepitation, significant however only for 1 of the investigators (prevalence rate ratios 2.1 and 3.2). The associations for pain by knee bending were not significant (prevalence rate ratios 2.6 and 2.5). 
Table 3. Knee osteoarthritis among the subjects with and without clinical signs of intraarticular and retropatellar crepitation, pain by kneeling 10 times, by investigator.

\begin{tabular}{|c|c|c|c|c|}
\hline & \multirow[t]{2}{*}{ Total (N) } & \multicolumn{3}{|c|}{$\begin{array}{c}\text { Radiological knee } \\
\text { osteoarthritis, grades 2-4 }\end{array}$} \\
\hline & & N & $\%$ & P-value \\
\hline \multicolumn{5}{|c|}{ Intraarticular crepitation } \\
\hline $\begin{array}{l}\text { No } \\
\text { Yes }\end{array}$ & $\begin{array}{r}129 \\
21\end{array}$ & $\begin{array}{r}10 \\
7\end{array}$ & $\begin{array}{r}7.8 \\
33.3\end{array}$ & 0.003 \\
\hline Investig & & & & \multirow[b]{2}{*}{0.001} \\
\hline $\begin{array}{l}\text { No } \\
\text { Yes }\end{array}$ & $\begin{array}{r}132 \\
18\end{array}$ & $\begin{array}{r}10 \\
7\end{array}$ & $\begin{array}{r}7.6 \\
38.9\end{array}$ & \\
\hline \multicolumn{5}{|c|}{ Retropatellar crepitation } \\
\hline $\begin{array}{c}\text { Investig } \\
\text { No } \\
\text { Yes }\end{array}$ & $\begin{array}{r}119 \\
31\end{array}$ & $\begin{array}{r}11 \\
6\end{array}$ & $\begin{array}{r}9.2 \\
19.4\end{array}$ & 0.12 \\
\hline \multicolumn{5}{|c|}{ Investigator 2} \\
\hline $\begin{array}{l}\text { No } \\
\text { Yes }\end{array}$ & $\begin{array}{r}123 \\
27\end{array}$ & $\begin{array}{r}10 \\
7\end{array}$ & $\begin{array}{r}8.1 \\
259\end{array}$ & \multirow[t]{2}{*}{0.02} \\
\hline \multicolumn{4}{|c|}{$\begin{array}{l}\text { Pain by knee bending } \\
10 \text { times }\end{array}$} & \\
\hline Investig & & & & \multirow[b]{2}{*}{0.07} \\
\hline $\begin{array}{l}\text { No } \\
\text { Yes }\end{array}$ & 129 & 12 & 9.3 & \\
\hline \multicolumn{5}{|c|}{ Investigator 2} \\
\hline $\begin{array}{l}\text { No } \\
\text { Yes }\end{array}$ & $\begin{array}{r}138 \\
12\end{array}$ & $\begin{array}{r}14 \\
3\end{array}$ & $\begin{array}{l}10.1 \\
25.0\end{array}$ & 0.14 \\
\hline
\end{tabular}

\section{Discussion}

Radiological knee osteoarthritis, grades $2-4$, was mainly found among the subjects $\geq 50$ years of age, among the subjects with knee complaints within the last 12 months, and among the floorlayers.

Floorlayers $\geq 50$ years of age had an increased prevalence of radiological knee osteoarthritis grades $2-4$, compared with the other 2 trades. The differences, however, were not significant as judged by the $95 \%$ confidence intervals. This test for statistical significance, however, is conservative. The prevalence of radiological knee osteoarthritis among the carpenters, all and for the subgroup $\geq 50$ years of age, was similar to that of the compositors. These results indicate that knee-straining work during most hours of a workday for many years may be a risk factor for the development of knee osteoarthritis. Although the numbers are small, this interpretation is supported by the finding that all cases of knee osteoarthritis grades $3-4$ were found among floorlayers $\geq 50$ years of age (4 out of 7 cases with knee osteoarthritis grades 2-4). Furthermore, for the subjects $\geq 50$ years of age, the combination of complaints and radiological knee osteoarthritis was significantly higher among the floorlayers than among the compositors. For the subjects $\geq 50$ years of age, there was a remarkably stronger association between radiological knee osteoarthritis and knee complaints for the floorlayers than for the other 2 trades.
An explanation for the differences between the trades could be that in more knee-straining work a similar degree of osteoarthritis produces more pain.

Subjects who participated in the radiological examination were selected at random from those who participated in the clinical examination, stratified by trade and complaint status. None of those invited to participate in the radiological examination declined. Therefore, if differential selection should explain the results, this selection would have to work at the level of agreement to participate in the clinical examination or completing the questionnaire. The questionnaire response rates were $85 \%, 79 \%$, and $78 \%$ for the floorlayers, carpenters, and compositors, respectively (5). Among the subjects without knee complaints within the last 12 months, $56 \%$ of the floorlayers, $56 \%$ of the carpenters, and $50 \%$ of the compositors agreed to participate in the clinical examination (including those with previous knee trauma or rheumatic disease). The similar figures for those with knee complaints were $66 \%, 69 \%$, and $70 \%$. These differences are small, and differential selection cannot explain the results.

We have found only 1 radiological study of knee osteoarthritis among floorlayers (4), and no studies of knee osteoarthritis among carpenters. Kivimäki et al (4) found no difference in the frequency of severe knee osteoarthritis among 25-to-49-year-old floorlayers compared with painters, a finding in accordance with our results. Studies from the 1950s showed an increased prevalence of radiological knee osteoarthritis in miners when they were compared with different reference groups without kneeling or squatting work $(1,7)$. These findings were supported in a more recent German study (2) of 50-yearold miners compared with 50-year-old referents without knee-straining work. Kneeling, squatting, or crawling work positions were also associated with an increased prevalence of radiological knee osteoarthritis in an American population study of more than 4000 subjects over 55 years of age (8).

A few other studies have found a positive association between knee-straining work and a diagnosis of knee osteoarthritis based on a combination of X-ray findings, a physical examination and symptoms for pipefitters ( 3 , 9) and welders and shipbuilders (3).

Subjects with knee-straining tasks often have heavy physical work, and vice versa. Some studies indicate that heavy physical work is a risk factor for knee osteoarthritis $(10-14)$, but they do not separate the possible effects of heavy physical work from the effects of knee-straining work positions.

We found an increased frequency of knee osteoarthritis among floorlayers but not among carpenters. We consider the work of the 2 groups to be fairly similar with respect to physical load and lifting, and we have shown that floorlayers have more knee-straining work than 
carpenters. In our study, therefore, knee-straining work positions rather than physical work load seem to be the more important risk factor. This assumption is supported by the results of a study by Enderlein et al (3).

The radiological interrater agreement on the degree of knee osteoarthritis was moderately good, with a kappa coefficient of 0.52 , considering all grades, and 0.61 for grades $2-4$ versus grades $0-1$.

Kellgren \& Lawrence (1) had 4 radiologists assessing radiological findings from miners, heavy manual workers, and office workers. These 4 investigators found $2,3,5$, and 6 cases of severe knee osteoarthritis among the miners, $0,0,1$, and 1 among the heavy manual workers, and none among the office workers. Their results do not suggest better interrater agreement than in our study. Intrarater agreement is naturally higher than interrater agreement. Thus Felson et al (15) found an intrarater agreement of 0.85 using the same criteria. McAlindon et al (16) found an intrarater agreement of 1.00 and 0.69 for medial and lateral compartment osteoarthritis, respectively, using dichotomized data. It was not clear, however, if they dichotomized at grade 2 or 3 .

The radiographs in our study were made with the subjects lying down. Compared with radiographs made in the standing position our results may underestimate the prevalence of knee osteoarthritis. Underestimation may also have resulted from not having assessed patellofemoral osteoarthritis $(16,17)$. Underestimation may have lowered the power of our study, but should not change the pattern of relationships between knee osteoarthritis and other factors.

We found a positive association between radiological knee osteoarthritis and clinical findings of intraarticular and retropatellar crepitation. The association was similar for the 2 clinical investigators even though the interrater reliability of the findings was only low to moderate (5). Similar data from epidemiologic studies are sparse. However, Wickström et al (18) also reported a positive relation between physical examination signs and radiological knee osteoarthritis in their study of concrete reinforcement workers.

We found an increased frequency of knee osteoarthritis for floorlayers $\geq 50$ years of age but not for floorlayers $<50$ years of age. This finding is in agreement with the findings of an American population study (8) and a study by Kivimäki et al (4) of floorlayers. In future epidemiologic studies it is recommended that more sensitive methods be used or developed to detect early stages of osteoarthritis in younger populations to know more precisely when they appear.

In conclusion, our data suggest that work in which a considerable amount of time is spent in knee-straining positions may be a risk factor for developing radiologically determined knee osteoarthritis above the age of 50 years.
Radiological knee osteoarthritis was positively associated with self-reported knee complaints and with clinical signs of intraarticular crepitation.

\section{Acknowledgments}

The study was supported by the Danish Working Environment Foundation (Arbejdsmiljøfondet, 1992-18, 1993-45)

\section{References}

1. Kellgren JH, Lawrence JS. Rheumatism in miners. Part II: Xray study. Br J Ind Med 1952;9:197-207.

2. Greinemann $\mathrm{H}$. Argumente gegen die Anerkennung von Kniegelenkarthrosen nach Berufsbelastung als Berufskrankheit. Unfallchirurgie 1988;91:374—80.

3. Enderlein G, Kasch J. Modellierung von Dosis-Wirkungsbezeihungen für expositionsabhängige Veränderungen am Beweungsapparat. Z Gesamte Hyg 1989;35(4):215-8.

4. Kivimäki J, Riihimäki H, Hänninen K. Knee-disorders in carpet and floor layers and painters. Scand J Work Environ Health 1992;18:310 - 6 .

5. Jensen LK, Petersen IP, Eenberg W, Bergmann I, Løgager V, Sinding J, et al. Knæbelastning og knælidelser blandt gulvlaggere og tømrere [Knee-strain and knee-disorders among floorlayers and carpenters]. Copenhagen: The Danish Working Environment Foundation, 1996. Abstract in English.

6. Kellgren JH, Lawrence JS. Atlas of standard radiographs, vol 2: the epidemiology of chronic rheumatism. Oxford: Blackwells Scientific Publications, 1963.

7. Lawrence JS. Rheumatism in miners, part III: occupational factors. Br J Ind Med 1955;12:249—61.

8. Anderson J, Felson DT. Factors associated with osteoarthritis and the knee in the first national health and nutrition examination survey (HANES I). Am J Epidemiol 1988;128(1):17989.

9. Von Nauwald G. Untersuchungen zur Häufigkeit professioneller kniegelenkserkrankungen bei älteren Rohrschlossern im Hochseeshiffbau. Beitr Orthop Traumatol 1986;33:124-8.

10. Jensen LK, Eenberg W. Occupation as a risk factor for knee disorders [review]. Scand J Work Environ Health 1996; 22:165-75.

11. Vingård E, Alfredsson L, Goldie I, Hogstedt C. Occupation and osteoarthrosis of the hip and knee: a register-based cohort study. Int J Epidemiol 1991;20(4):1025-31.

12. Kohatsu ND, Schurman DJ. Risk factors for the development of osteoarthrosis of the knee. Clin Orthop 1990;261:242-6.

13. Vingård E, Alfredsson L, Evy F, Christer H. Disability pensions due to musculo-skeletal disorders among men in heavy occupations: a case-control study. Scand J Soc Med 1992 20:31-6.

14. Lindberg H, Montgomery F. Heavy labor and the occurrence of gonarthrosis. Clin Orthop 1987;214:235-6.

15. Felson DT, Naimark A, Anderson J, Kazis L, Castelli W, Meenan RF. The prevalence of knee osteoarthritis in the elderly: the Framingham Osteoarthritis Study. Arthritis Rheum 
1987;30:914-8.

16. McAlindon TE, Snow S, Cooper C, Dieppe PA. Radiographic patterns of osteoarthritis of the knee joint in the community: the importance of the patellofemoral joint. Ann Rheum Dis 1992;51:844-9.

17. Jacobsen LTH. Definition of osteoarthritis in the knee and hand. Ann Rheum Dis 1996;55:556-8.

18. Wickström $G$, Hänninen $K$, Mattsson $T$, Niskanen $T$, Riihimäki $\mathrm{H}$, Waris $\mathrm{P}$, et al. Knee degeneration in concrete reinforcement workers. Br J Ind Med 1983;40:216—9.

Received for publication: 31 March 1999 